\title{
Patellar tendinopathy: some aspects of basic science and clinical management
}

School of Human Kinetics, University of British Columbia,

Vancouver, Canada K M Khan

J E Taunton

Victorian Institute of Sport Tendon Study Group, Melbourne, Victoria, Australia K M Khan

J L Cook

Department of Orthopaedic Surgery, University of Aberdeen Medical School, Aberdeen, Scotland, United Kingdom N Maffulli

Department of Medicine, University of Melbourne, Royal Melbourne Hospital,

Parkville, Victoria, Australia

B D Coleman

J L Cook

Griffiths University, Gold Coast, J L Cook

Allan McGavin Sports Medicine Centre, University of British Columbia, Vancouver, Canada

J E Taunton

Correspondence to: Dr K Khan, School of Human Kinetics, University of British Columbia, 6081

University Boulevard,

Vancouver V6T 1Z1,

Canada.

Accepted for publication 27 May 1998 Queensland, Australia

\author{
K M Khan, N Maffulli, B D Coleman, J L Cook, J E Taunton
}

Tendon injuries account for a substantial proportion of overuse injuries in sports. ${ }^{1-6}$ Despite the morbidity associated with patellar tendinopathy in athletes, management is far from scientifically based. ${ }^{7}$ After highlighting some aspects of clinically relevant basic science, we aim to $(a)$ review studies of patellar tendon pathology that explain why the condition can become chronic, $(b)$ summarise the clinical features and describe recent advances in the investigation of this condition, and $(c)$ outline conservative and surgical treatment options.

\section{Method}

A computerised literature search of the entire MEDLINE database, covering the years 1966 to the present, was conducted for this review. Table 1 lists the keywords used in the search. All relevant articles were retrieved, either locally or by interlibrary loan. The search was not limited to the English literature, and articles in all journals were considered. The authors' personal collections of papers and any relevant personal correspondence were also included. The references selected were reviewed by the authors, and judged on their contribution to the body of knowledge of this topic. The conduct and validity of any clinical studies was carefully considered, and the outcomes of management protocols were carefully scrutinised. Case reports were excluded, unless they mentioned a specific association with the condition which was thought to be relevant to the discussion. Only papers that made a significant contribution to the understanding of this condition were included in the review. This left a total of 315 publications, 52 of which were directly related to patellar

Table 1 Keywords used to search the MEDLINE database

\begin{tabular}{lll}
\hline $\begin{array}{l}\text { Keywords } \\
\text { Patellar tendon } \\
\text { Athletic injuries } \\
\text { Biomechanics } \\
\text { Collagen }\end{array}$ & $\begin{array}{l}\text { Extracellular matrix } \\
\text { Incidence } \\
\text { Postoperative complications } \\
\text { Pubheadings }\end{array}$ & $\begin{array}{l}\text { Tendinitis } \\
\text { Tendon } \\
\text { Tendon injuries }\end{array}$ \\
$\begin{array}{l}\text { Abnormalities } \\
\text { Anatomy and histology }\end{array}$ & Growth and development & \\
Blood supply & Injuries & Pathophysiology \\
Chemistry & Innervation & Surgery \\
Cytology & Metabolism & Transplantation \\
Drug effects & Pathology & Ultrasonography \\
Magnetic resonance imaging & Physiology & Ultrastructure \\
\hline
\end{tabular}

tendinopathy, and the remainder to tendon or tendon structure in general.

\section{Anatomy}

The patellar tendon, the extension of the common tendon of insertion of the quadriceps femoris muscle, extends from the inferior pole of the patella to the tibial tuberosity. It is about $3 \mathrm{~cm}$ wide in the coronal plane and 4 to $5 \mathrm{~mm}$ deep in the sagittal plane. Macroscopically it appears glistening, stringy, and white.

\section{BLOOD SUPPLY}

The blood supply has been postulated to contribute to patellar tendinopathy. ${ }^{8}{ }^{9}$ The patellar tendon receives its vascularisation through the anastomotic ring which lies in the thin layers of loose connective tissue covering the dense fibrous expansion of the rectus femoris. The main contributors are the medial inferior genicular, lateral superior genicular, lateral inferior genicular, and the anterior tibial recurrent artery. ${ }^{10} 11$ The blood supply to the proximal portion of the patellar tendon enters precisely around the region that is most commonly affected by patellar tendinopathythe proximal posterior aspect of the tendon.

A commonly held belief is that the patellar tendon has a "relatively avascular osseotendinous junction" (Scapinelli ${ }^{11}$ quoted from McLoughlin et $\left.a l^{9}\right)$. Scapinelli ${ }^{11}$ reported that, although the distal attachment of the patellar tendon to the tibial tuberosity includes an "avascular zone between ligament and bone", the proximal attachment abuts the inferior half of the patella and the infrapatellar fat pad, both of which are richly vascularised. Thus the proximal patellar tendon is well vascularised. Blood flow at rest, however, does not necessarily correlate with blood flow during activity. Recent technical advances could permit further study of patellar tendon vasculature at rest and during quadriceps stretch and contraction. ${ }^{12}$

\section{Mechanical loading in sport}

Tendon displays a characteristic stress-strain curve $^{13}$ (fig 1). The classic crimped configuration of collagen fibres and fibrils at rest disappears when tendon is stretched by about $2 \%{ }^{4}{ }^{14}$ With further stretch to about $5 \%$ elongationthat is, load in sport-tendon fibres become more parallel and the tendon has a relatively 


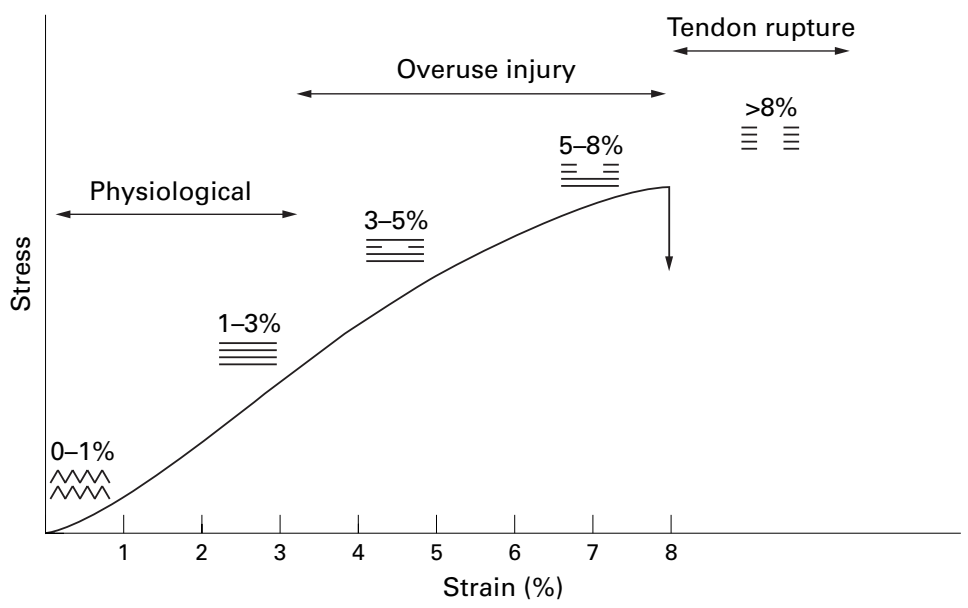

Figure 1 Stress-strain curve for tendon. Adapted from Leadbetter. ${ }^{20}$

linear response to stress. Beyond this elongation, tendon microfailures occur. ${ }^{1}$ Collagen fibres slide past one another as cross links fail. ${ }^{15}$ With even further strain, the tensile failure of fibres themselves, combined with shear failure, causes macroscopic damage in an unpredictable fashion. ${ }^{15}$

A force of $0.5 \mathrm{kN}$ is experienced in level walking, and forces within the patellar tendon may reach $8 \mathrm{kN}$ during landing from a jump, up to $9 \mathrm{kN}$ during fast running and $14.5 \mathrm{kN}$ during competitive weight-lifting (about 17 times bodyweight). ${ }^{16-18}$ Basketball players jump on average 70 times per game, and the vertical component of each ground reaction force in a jump is around six to eight body weights. ${ }^{19}$ Thus sports activities can impose stresses high enough to cause fibre failure.

\section{Patellar tendon pathology}

NOMENCLATURE FOR TENDON PATHOLOGY

There is a lack of consistent nomenclature for histopathological findings, and a standardised nomenclature has been proposed ${ }^{12021}$ (table 2).

PATHOLOGY OF JUMPER'S KNEE

As recently as 1994, the pathology underlying patellar tendinopathy was not clearly defined, ${ }^{22}$ probably reflecting confusion arising from dif- ferences in nomenclature rather than a paucity of data. Macroscopically, the patellar tendon of patients with jumper's knee contain soft, ${ }^{23}$ yellow-brown, and disorganised tissue ${ }^{23-25}$ evident even to the naked eye. ${ }^{26-31}$ This macroscopic appearance is commonly labelled "mucoid" degeneration. ${ }^{8629-31}$ Occasionally, authors have reported "hyaline" degeneration, ${ }^{25} 27$ which is characterised by hardness rather than the softness inherent in mucoid degeneration. ${ }^{1}$

Under light microscopy, the tendon of patients with jumper's knee is characterised by abnormal collagen, tenocytes, and vasculature. It does not consist of tight parallel collagen bundles but appears amorphous and disorganised with collagen replaced by degenerative and necrotic tissue. Clefts in collagen suggest microtearing. ${ }^{30}$ The characteristic reflective polarised light appearance of normal collagen is lost. ${ }^{27}{ }^{32}$ Alcianophilic ground substance, ${ }^{32}$ consisting of glycosaminoglycans and proteoglycans, ${ }^{33}$ is markedly increased. Tenocytes lose their fine spindle shape, and nuclei appear more rounded. ${ }^{2126}{ }^{30}$ There is abnormal small vessel ingrowth. ${ }^{8} 2630$ Very similar histopathological changes occur in patients with Achilles tendinopathy. ${ }^{34}$

The presence of inflammatory cells in the excision biopsy samples from patients with patellar tendinopathy is sometimes debated. Two recent papers, coauthored by specialist pathologist authors who analysed all specimens in each study, ${ }^{27}{ }^{32}$ reported the total absence of inflammatory cells from tissue from patients with jumper's knee, even at the periphery of abnormal tissue and in patients who had only had symptoms for four months. ${ }^{32}$ Fibroblasts, however, were more plentiful than in the normal tendon, ${ }^{8}{ }^{26-31}$ 35-37 $^{25}$ and these may have appeared to be inflammatory cells to earlier authors. Papers reporting the presence of inflammatory cells have not mentioned staining methods or the expertise of the pathologist(s) reviewing specimens, ${ }^{25} 2838-40$ and only one $^{38}$ included a pathologist author. ${ }^{25} 283940$

This suggests that, in most cases, the tendons of patients suffering patellar tendinopathy appear to have a tendinosis, ${ }^{32}$ a

Table 2 Pathological classification of tendon disorders (from Clancy ${ }^{21}$ )

\begin{tabular}{|c|c|c|}
\hline Pathological label & Concept (macroscopic pathology) & Histological finding \\
\hline Tendinosis & $\begin{array}{l}\text { Intratendinous degeneration (commonly due to aging, } \\
\text { microtrauma, vascular compromise) }\end{array}$ & $\begin{array}{l}\text { Non-inflammatory intratendinous } \\
\text { collagen degeneration with fibre } \\
\text { disorientation, hypocellularity, } \\
\text { scattered vascular ingrowth, } \\
\text { occasional local necrosis or } \\
\text { calcification }\end{array}$ \\
\hline Paratenonitis & $\begin{array}{l}\text { Inflammation of the outer layer of the tendon (paratenon) } \\
\text { alone, whether or not the paratenon is lined by synovium }\end{array}$ & $\begin{array}{l}\text { Inflammatory cells in the } \\
\text { paratenon or peritendinous areolar } \\
\text { tissue }\end{array}$ \\
\hline Paratenonitis with tendinosis & $\begin{array}{l}\text { Paratenon inflammation associated with intratendinous } \\
\text { degeneration }\end{array}$ & $\begin{array}{l}\text { Inflammatory cells in the } \\
\text { paratenon or peritendinous areolar } \\
\text { tissue with loss of tendon collagen, } \\
\text { fibre disorientation, scattered } \\
\text { vascular ingrowth and no } \\
\text { prominent intratendinous } \\
\text { inflammation }\end{array}$ \\
\hline Tendinitis & $\begin{array}{l}\text { Symptomatic degeneration of the tendon with vascular } \\
\text { disruption and inflammatory repair response }\end{array}$ & $\begin{array}{l}\text { Acute haemorrhage and tear, } \\
\text { inflammation superimposed on } \\
\text { existing degeneration. Includes the } \\
\text { conditions of tendon strain and } \\
\text { tear. }^{1}\end{array}$ \\
\hline
\end{tabular}




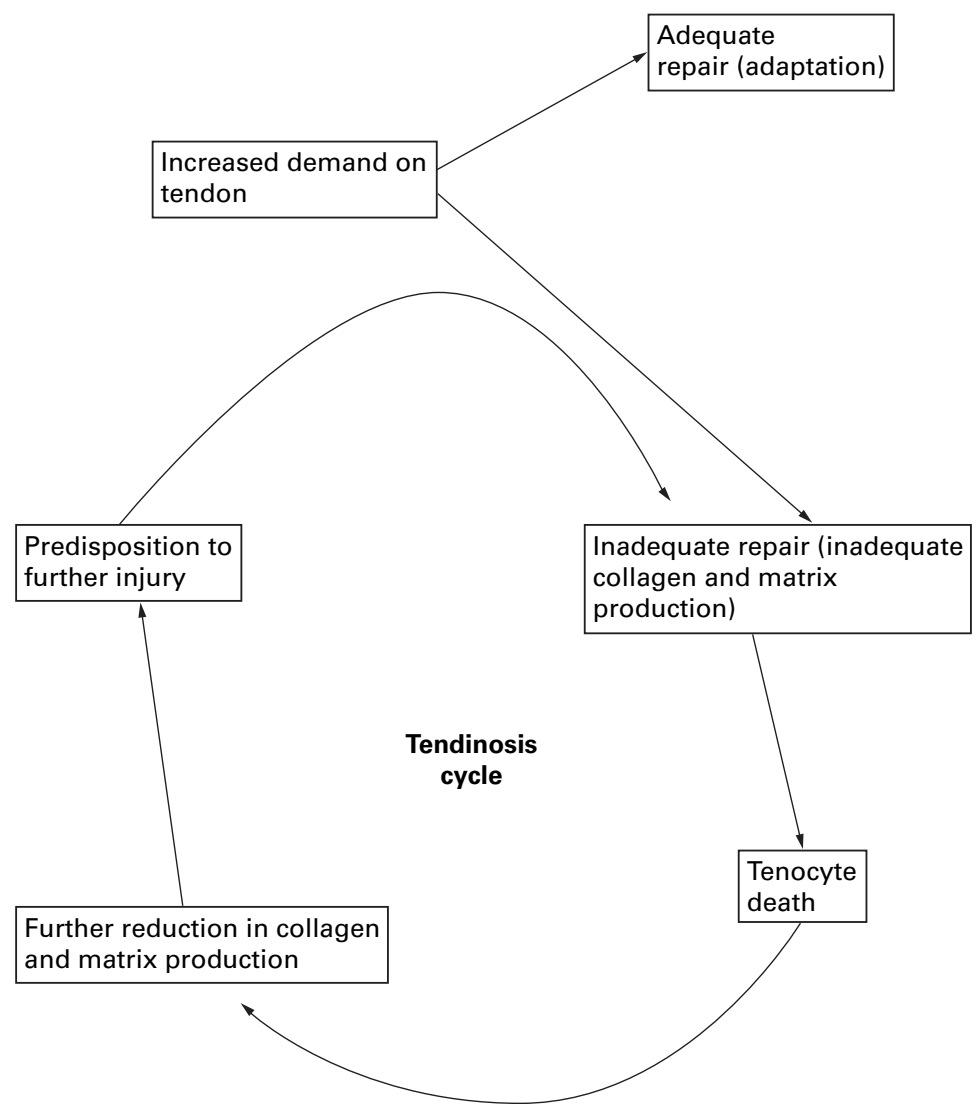

Figure 2 A theoretical model illustrating how tendon injury may precipitate a vicious cycle ("tendinosis cycle") of further injury. Modified from Leadbetter. ${ }^{20}$

degenerative condition that would be expected to heal more slowly than an acute inflammatory condition. Thus sudden repeated tensile overloading may cause microtearing and fraying of tendon fibres followed by focal degeneration particularly at the tendon insertion to the patella. ${ }^{39} 41$

Acute tendon ruptures are outside the scope of this review, but the pathology preceding such events is of interest. In 53 cases of spontaneous patellar tendon rupture, intratendinous pathology included hypoxic degenerative change, mucoid degeneration, tendolipomatosis, and calcifying tendinopathy or a combination of these subcategories of tendinosis. ${ }^{42}$ Thus tendinosis preceded acute tendon rupture but remained symptomless in these cases. ${ }^{43}$

These findings lead us to recommend that consistent nomenclature for tendon pathology (table 2) be widely adopted so that clear histological criteria exist for the conditions of paratenonitis, tendinosis, and the condition where these coexist (paratenonitis with tendinosis). It appears that intratendinous inflammation, "tendinitis", occurs mainly after tendon ruptures.

REPAIR OF MECHANICALLY DAMAGED TENDON Because of its slow metabolic rate, tendon tissue was once thought to be inert. ${ }^{45}{ }^{46}$ Oxygen consumption of mature collagen is about $8-10$ times lower than that of liver and skeletal muscle. ${ }^{47}{ }^{48}$ Tendon maintenance relies on the tenocyte producing collagen, a protein with a turnover time of 50 to 100 days. ${ }^{49} 50$
When loading causes microdamage, tenocytes must increase collagen and matrix production. However, even when tenocyte metabolism is increased, tendon scar maturation remains a slow process. Animal experiments suggest that this may take four months in the calcaneal tendon of the rabbit and at least 14 months in the superficial digital flexor tendon of the horse..$^{51}$ If a tendon is given inadequate time to repair, tenocytes may die as the result of excessive strain. Collagen and matrix synthesis is then further reduced, making the remaining tissue even more vulnerable to further damage (fig 2).

\section{Clinical aspects \\ NOMENCLATURE}

Athletes whose sports involve repetitive sudden ballistic movements of the knee may develop anterior knee pain associated with tenderness at the inferior pole of the patella, a clinical syndrome commonly called "jumper's knee". ${ }^{35}$ In this condition ultrasound examination and magnetic resonance imaging (MR) reveal abnormal signals at the junction of the patella and the patellar tendon. Other names for this condition include "patellar tendinopathy", "patellar tendinosis", "patellar tendinitis", "patellar tendonitis", "patella tendon disorder", "insertion tendinitis of the patellar tendon", "partial rupture of the patellar tendon", and "patellar apicitis". "Peritendinitis of the patellar tendon" and acute ruptures are normally not encompassed by these terms.

However, as inflammatory peritendinous lesions can also contribute to patients' symptoms, we believe the term tendinopathy is the most appropriate clinical description for tendon conditions - that is, patellar tendinopathy, Achilles tendinopathy. ${ }^{44}$ In our practice, the term patellar tendinopathy encompasses the lesion associated with pain and tenderness at the lower point of the patella and lesions of the main body of the tendon. ${ }^{28}{ }^{40}$ The latter are less common than the former and seem to involve the whole of the tendon instead of mainly its posterior aspect. ${ }^{52}$ The term tendinopathy can be used to describe both acute and overuse conditions. This system of nomenclature avoids amibiguity as the terms tendinosis, paratendinitis, and tendinitis are reserved as pathological labels.

EPIDEMIOLOGY

Jumper's knee is most commonly seen in athletes from the sports of basketball, volleyball, football, soccer, high jump, long jump, tennis, and running, ${ }^{35} 5354$ as well as telemark and mogul skiing. As elite athletes appear to be affected more than recreational athletes, ${ }^{22}{ }^{53}$ the frequency and intensity of training and competition may influence the development of symptoms. ${ }^{55}$ Other skill factors, however, such as quick acceleration, deceleration, stopping, and cutting actions, ${ }^{56-58}$ and greater jumping ability may also predispose to tendinopathy. ${ }^{58}$ Anecdotal evidence and the gender ratio of patients in published clinical studies ${ }^{59}$ suggest that patellar tendinopathy is more prevalent in 


\section{VICTORIAN INSTITUTE OF SPORT}

ASEESSWEN SCOFI

1. For how many minutes can you sit pain free?

$0 \min$

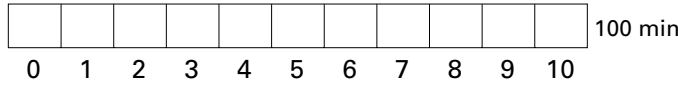

2. Do you have pain walking downstairs with a normal gait cycle?

Strong

severe
pain

3. Do you have pain at the knee with full active non-weightbearing knee extension?

\begin{tabular}{l|l|l|l|l|l|l|l|l|l|l|l|}
$\begin{array}{l}\text { Strong } \\
\text { severe } \\
\text { pain }\end{array}$ & 0 & & & & & & & & & & \\
No pain
\end{tabular}

4. Do you have pain when doing a full weight-bearing lunge? Strong

severe

pain

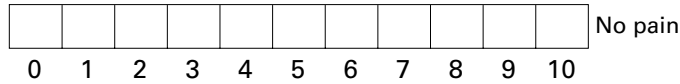

5. Do you have problems squatting?

Unable

\begin{tabular}{|c|c|c|c|c|c|c|c|c|c|c|}
\hline & & & & & & & & & & \\
\hline 0 & 1 & 2 & 3 & 4 & 5 & 6 & 7 & 8 & 9 & 10 \\
\hline
\end{tabular}

6 . Do you have pain during or immediately after doing

10 single leg hops?

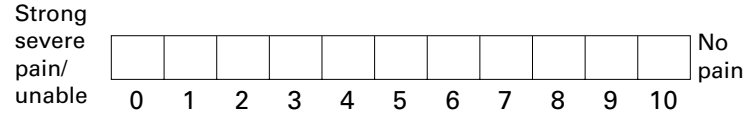

7. Are you currently undertaking sport or other physical activity?

$0 \square$ Not at all

$4 \square$ Modified training \pm modified competition

$7 \square$ Full training \pm competition but not at same level as when symptoms began

$10 \square$ Competing at the same or higher level as when symptoms began

8. Please complete EITHER A, B or $\mathbf{C}$ in this question.

- If you have no pain while undertaking sport please complete Q8A only.

- If you have pain while undertaking sport but it does not stop you from completing the activity, please complete Q8B only.

- If you have pain that stops you from completing sporting activities, please complete $\mathbf{0 8 C}$ only

A. If you have no pain while undertaking sport, for how long can you train/practise?

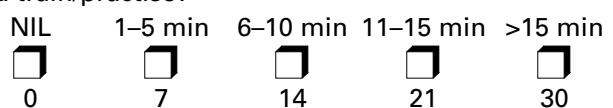

OR

B. If you have some pain while undertaking sport, but it does not stop you from completing your training/practice, for how long can you train/practise?

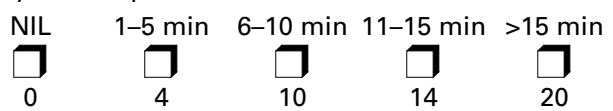

POINTS

OR

C. If you have pain that stops you from completing your training/practice, for how long can you train/practise?

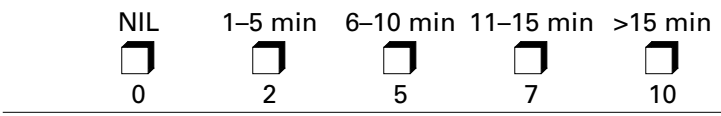

TOTAL SCORE

POINTS

Figure 3 Victorian Institute of Sport Assessment (VISA) scale: an index of severity of symptoms of jumper's knee. ${ }^{63}$ men than women, but no controlled studies have considered this question.

Blazina et $a l^{\beta 5}$ were the first authors to recognise that jumper's knee is not always a benign self limiting disorder. Symptoms can persist despite treatment, and there is a high rate of recurrence. ${ }^{59}$ This condition has forced some elite athletes to retire prematurely.

HISTORY AND PHYSICAL EXAMINATION

The clinical diagnosis of patellar tendinopathy is based on patients' subjective reports of pain related to activity levels. ${ }^{35}$ The onset of symptoms is often insidious, but usually relates to an increase in frequency or intensity of activity involving rapid repetitive ballistic movements of the knee joint. ${ }^{53}$ Initially, athletic patients will complain of a dull ache in the anterior knee after strenuous activity. Athletes who continue to play with these symptoms eventually experience pain that interferes with performance. ${ }^{35}$ Patients also commonly complain of pain when seated for long periods and when ascending and descending stairs.

The key physical finding in patellar tendinopathy is tenderness at the inferior pole of the patella or in the main body of the tendon when the knee is fully extended and the quadriceps relaxed. When the knee is flexed to 90 degrees, thus putting the tendon under tension, tenderness significantly decreases and often disappears altogether (J B King and N Maffulli, unpublished observations). There are generally few classical signs of soft tissue inflammation. ${ }^{35} 53$ The main differential diagnosis is with the patellofemoral syndrome, ${ }^{6061}$ and the two conditions can coexist.

CLINICAL GRADING

There are several systems of grading jumper's knee according to the severity and timing of knee pain. ${ }^{22} 30355762$ The reliability of these scales has never been tested, and they are often incapable of discriminating between patients with widely differing symptoms. They cannot be used to grade recovery. Recently, we developed a 100 point scoring scale to assess severity of jumper's knee according to symptoms and function ${ }^{63}$ (fig 3 ).

\section{Imaging}

Ultrasonography and MR are the imaging modalities of choice in patients with tendon disorders. ${ }^{64}{ }^{65}$ Although computed tomography can image the patellar tendon and has been shown to be of some prognostic value, ${ }^{28}{ }^{40}$ it does not offer any significant advantage over methods not using ionising radiation.

ULTRASONOGRAPHIC APPEARANCE OF THE PATELLAR TENDON IN JUMPER'S KNEE Patellar tendons in patients with jumper's knee have decreased echogenicity, containing either a focal sonolucent region ("cyst") or diffuse hypoechogenicity. ${ }^{32} 36$ 37 65-68 Irregularity of the tendinous envelope, intratendinous calcification, and erosion of the patellar tip also occur. ${ }^{136}$ The characteristic sonographic hypoechogenic regions may represent fluid accumu- 
lation near hydrophilic proteoglycans of exposed intercellular matrix of the damaged tendon. ${ }^{69}$

Ultrasonography has been used to (a) detect preclinical lesions in athletes, ${ }^{22}(b)$ detect patellar tendon pathology, ${ }^{29}(c)$ assess its severity, $(d)$ monitor progress of the patellar tendon in patients being treated for patellar tendinopathy ${ }^{53}(e)$ provide objective indications for surgery, ${ }^{36}{ }^{37}(f)$ assess tendon healing after surgery, ${ }^{70}$ and $(g)$ image the remaining portions of the patellar tendon after its central third has been harvested for use as a graft for anterior cruciate ligament reconstruction. ${ }^{71-74}$ Can ultrasonography perform all of these roles?

\section{CLINICAL UTILITY OF PATELLAR TENDON} ULTRASONOGRAPHY

Most studies reporting the clinical significance of hypoechoic regions on tendon ultrasound examination have not compared their findings with those in controls matched for athletic level. A proportion of asymptomatic athletes have sonographic hypoechoic regions in their patellar tendons. In a group of volleyball players, $54 \%$ of asymptomatic knees contained patellar tendons with hypoechoic regions on ultrasonography. ${ }^{57}$ Similarly, $15 \%$ of basketball players with no past history of knee pain had abnormal tendon morphology on ultrasonography. ${ }^{75}$ Comparable findings have been reported in asymptomatic recreational athletes. ${ }^{76}$ Furthermore, a longitudinal study found that hypoechoic ultrasound regions in asymptomatic sportswomen did not predict subsequent development of symptoms. ${ }^{77}$ These data undermine the suggestion that ultrasonographic appearance can guide prognosis and management ${ }^{29}$ and they emphasise that a sonographic hypoechoic region is not, of itself, an indication for surgery. ${ }^{37} 77$

In the postoperative tendon, except in selected cases, ${ }^{54}{ }^{78}$ imaging does not appear to differentiate those patients who make a good recovery from those who continue to have tendon symptoms. ${ }^{80}$ Information from studies of the patellar tendon donor site in anterior cruciate reconstruction surgery suggests that it takes the patella up to two years to regain a normal appearance on ultrasound examination. ${ }^{71-74}$ Therefore clinical judgment should take precedence over imaging appearance in postsurgical management.

\section{MR OF THE PATELLAR TENDON}

The abnormal patellar tendon contains an oval or round area of high signal intensity on T1and T2- and the proton-density-weighted images at the tendon attachment or a focal zone of high signal intensity in the deep layers of the tendon insertion. ${ }^{273281}$ Tendons with patellar tendinopathy have increased anteroposterior diameter in the affected region. ${ }^{27} 5281$

The T2-weighted sequences (particularly the $\mathrm{T} 2{ }^{\star}$-weighted GRE sequences) have greater sensitivity than the $\mathrm{T} 1$-weighted protocols. $^{9273274}$ However, the T1-weighted signal can image most cases of patellar tendinopathy. In the Achilles tendon, MR detected abnormal tissue with greater sensitivity than ultrasonography. ${ }^{82}$ In the patellar tendon, the area of high signal on $\mathrm{T} 2{ }^{\star}$-weighted GRE sequence was significantly larger than the area of abnormal signal on ultrasound examination, ${ }^{32}$ but the biological significance of this finding was not investigated.

CLINICAL UTILITY OF PATELLAR TENDON MR MR scans could be used to identify the exact location and extent of tendon involvement, and help to exclude other clinical conditions such as bursitis and chondromalacia. ${ }^{81}$ Surgeons could use MR to assess the severity of patellar tendon disease and determine how much tendon to excise. ${ }^{2781}$

Disadvantages of MR include cost and also slow and often incomplete resolution of signal changes after surgical intervention. ${ }^{70}$ Whether MR abnormalities occur in asymptomatic patellar tendons has not been examined, but other tendons contain high-signal abnormality on MR in nearly a quarter of young volunteers. ${ }^{83}$

Abnormal signal without change in size must be interpreted with caution, as the normal patellar tendon has a range of appearances because of technical factors and intrinsic fibre differences. ${ }^{84}$ In particular, the "magic angle" phenomenon can result in false positive high-signal intensity on GRE T2 $2^{\star}$ - weighted images of normal tendon. ${ }^{32} 8586$

\section{Management of patellar tendinopathy}

Given the degree of morbidity associated with chronic tendon problems, and the extent of knowledge in certain areas of medical treatment, there is a surprising lack of scientific rationale for tendon treatment. ${ }^{1}$ Conservative and operative treatments of tendinopathies vary considerably among surgeons and across countries. Unfortunately, "there is little scientific evidence for the majority of treatments proposed and used for chronic tendon problems". ${ }^{70}$ Thus the treatment outlines suggested below are, at best, "empirical".

CONSERVATIVE MANAGEMENT

Conservative management regimens for jumper's knee are varied, and are usually based on the patient's subjective report of pain. Treatments include correction of predisposing factors, relative or absolute rest from aggravating high load activities, stretching and strengthening, physical therapy modalities, ice, massage, non-steroidal anti-inflammatory medication, corticosteroids by injection, or electrophoresis. ${ }^{617087}$

\section{Rest}

The question of whether players with patellar tendinopathy should rest completely is difficult, but we believe that athletes who present with patellar tendinopathy for the first time have their best opportunity to make a full recovery by resting from competition and undergoing a complete conservative management programme (see below) before returning pain-free to their sport. This approach respects our knowledge of tendon pathology, as there is likely to be an area of substantial intratendinous 


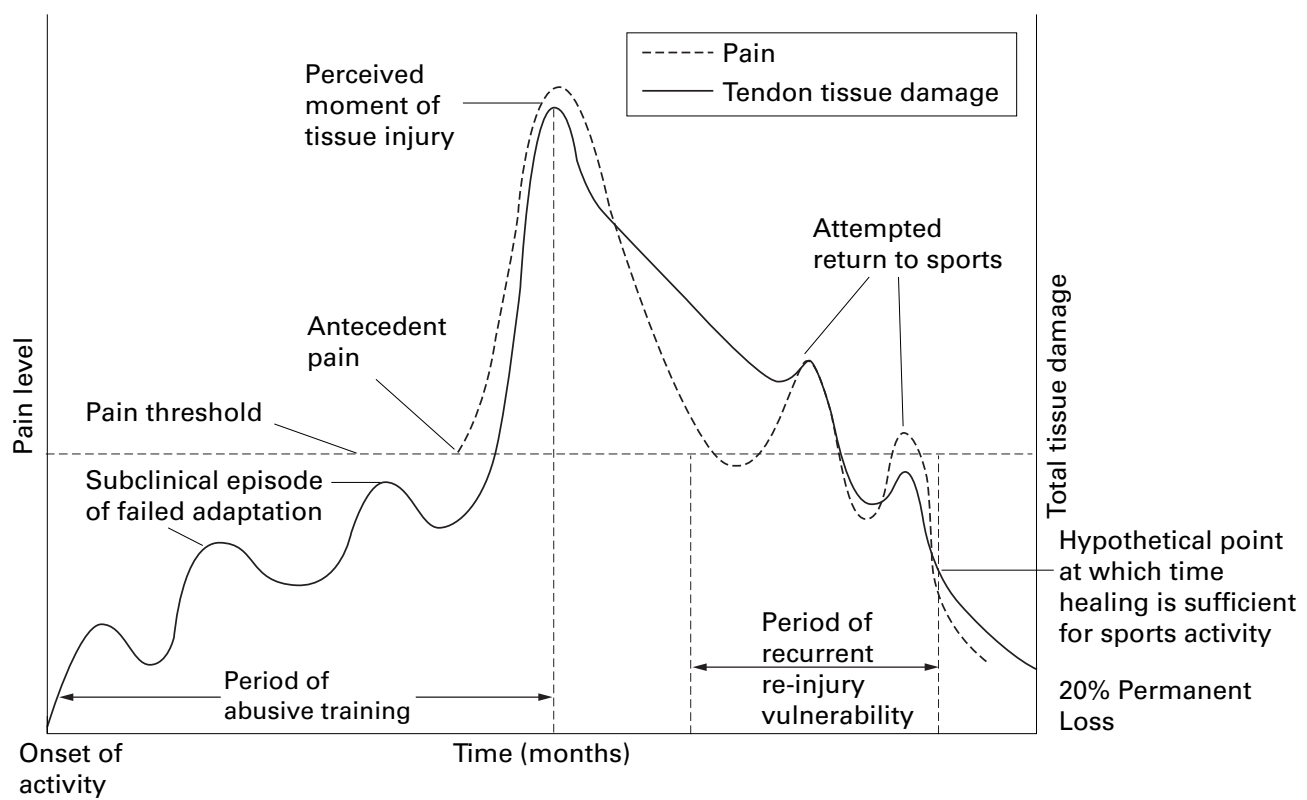

Figure 4 Schematic illustration of pain and tissue damage in overuse tendinopathy. Tendon pathology may begin well before symptoms arise. Therefore recovery may take months, even in patients who present with recent onset of symptoms. Adapted from Leadbetter. ${ }^{20}$

degeneration even if symptoms are recent (fig 4). This approach is advocated even in elite regular competitions - for example, an NBA season, premier league soccer, world league volleyball— but a compromise may be necessary immediately before one-off tournaments such as World Championships or Olympic Games. This conservative approach is often unacceptable to players (who have little pain) and to coaches (who are paid to have short term goals). A poor alternative may be a period of rest and rehabilitation taken at the end of a season. ${ }^{77}$

Decreasing the load on the tendon: technique, orthotics, braces, and straps

One approach to healing tendon tissue is to decrease its loading. This can be achieved by an athlete decreasing the number of jumps-for example, adjusting his/her style of playing. Another way to decrease tendon loading in basketball and volleyball is for players to ensure that they land from jumps on two feet instead of one. In the heat of competition, however, this is not always feasible. Orthotic devices worn in shoes and boots may decrease the load on the patellar, as well as the Achilles, tendon in individuals with excessive pronation.

Knee braces and straps such as the Chopat strap are commonly used to alter the load on the tendon. The Chopat $\operatorname{strap}^{61}$ (a tape attached just proximal to the patellar attachment to the tibia) supports the tibial attachment of the patellar tendon, but it probably does little to unload the insertion of the patellar tendon to the patella.

A new approach to patellar tendon bracing uses a semi-rigid patellar stay and buttress pad. Contained in a knee sleeve, this device aims to unload the quadriceps tendon and thus decrease the force transmitted through to the patellar tendon. As with other innovative therapies in patellar tendinopathy, rigorous research is required.

\section{Cryotherapy and physical modalities}

To control initial tissue response to tendon injury, most clinicians advise rest, cryotherapy, and anti-inflammatory medication (see below). Cryotherapy is thought to act by decreasing blood flow and metabolic rate, thereby limiting tissue damage. Electrical modalities that have been used in patellar tendinopathy include ultrasound, heat, interferential therapy, magnetic fields, pulsed magnetic and electromagnetic fields, transcutaneous electrical nerve stimulation (TENS), and laser. ${ }^{161} 88$ Ultrasound is commonly used in tendinopathy but its efficacy may be specific to wavelength and intensity. The true effects of all of these modalities remain unknown and require further investigation. Our management of tendinopathies generally includes cryotherapy, ultrasound, laser, magnetic fields as well as pulsed magnetic and electromagnetic fields. ${ }^{89}$

\section{Remedial massage}

Remedial massage aims to treat tendon tissue by having an effect on muscle stretch as well as by a direct effect on tendon cells. Muscle belly massage is thought to increase muscle compliance and decrease load on the tendon. Deep friction tendon massage may activate mesenchymal stem cells to stimulate a healing response. A controlled study failed to find any positive effects of massage treatment in patients with patellar tendinopathy. ${ }^{90}$ However, "fibrolysis", a form of deep frictional massage originally developed in Finland, has been successful in Achilles tendinopathy. ${ }^{91}$ Our clinical experience suggests that such a method warrants testing in the patellar tendon.

\section{Rehabilitation}

The stretching and strengthening programme of the whole muscle tendon unit of a chronically painful tendon is seen as a key treatment of patellar tendinopathy. ${ }^{1}$ Many 
Table 3 Eccentric squat programme for patellar tendinopathy. (As used at Allan McGavin Sports Medicine Centre, Vancouver, Canada) (modified from ref 17)

\begin{tabular}{|c|c|c|c|c|}
\hline \multicolumn{3}{|c|}{ Weekly schedule } & \multicolumn{2}{|c|}{ Resistance schedule } \\
\hline$\overline{\text { Day }}$ & Sets & Repeats & Week & Instructions \\
\hline 1 & 3 & 8 & 1 & No weight, slow drop \\
\hline 2 & 3 & 10 & 2 & No weight, fast drop \\
\hline 3 & 3 & 12 & 3 & $2 \mathrm{~kg}$ each hand, fast drop \\
\hline 4 & 3 & 14 & 4 & $4 \mathrm{~kg}$ each hand, fast drop \\
\hline 5 & 3 & 16 & 5 & $6 \mathrm{~kg}$ each hand, fast drop \\
\hline 6 & 3 & 18 & 6 & $8 \mathrm{~kg}$ each hand, fast drop \\
\hline 7 & 3 & 20 & After 6 weeks & Do $3 \times /$ week @ $8 \mathrm{~kg}, 3 \times 20$ repeats \\
\hline
\end{tabular}

rehabilitation methods have been described, but none has been scientifically tested as yet. Curwin and Stanish ${ }^{92}$ suggest a three stage conservative programme for patellar tendinopathy which corresponds to three stages of worsening severity of the condition..$^{35}$ Stage 1 consists of adequate warm up, ice after activity, local anti-inflammatory treatments, including non-steroidal anti-inflammatory drugs (NSAIDs), physiotherapy, including isometric quadriceps exercises, and an elastic knee support. In stage 2 a period of rest is added, together with some form of heat before activity. In stage 3 a prolonged period of rest is added..$^{92} 93$ The key eccentric element described is the drop squat from standing to about 100 $120^{\circ}$ of knee flexion. Patients are advised to perform three sets of 10 repetitions per session (one session daily). ${ }^{92} 93$

The proposers of this treatment programme emphasise the principles of training specificity, maximal loading, and progression. ${ }^{94} 95$ In basketball and volleyball players, specificity is achieved by prescribing activities that mimic jumping. Maximal loading occurs when patients feel their tendon pain in the third set of 10 repetitions. Progression is achieved by increasing the speed of movement or by increasing the external resistance, again using pain as a guide. Ice is used to cool the tendon after the eccentric training. A modified version of this protocol as used by one of us ( $\mathrm{J} \mathrm{E} \mathrm{T)} \mathrm{is}$ reproduced (table 3 ).

Some authors ${ }^{94}{ }^{95}$ contend that athletes often do not need to refrain from sport during this rehabilitation programme and that athletes become asymptomatic after six to eight weeks of exercise ${ }^{92}$ Under close clinical supervision to adjust the programme as needed, ${ }^{94}{ }^{95}$ this regimen brought complete relief to $30 \%$ of patients and a marked decrease in symptoms to a further $64 \% .^{92}$ The remaining $6 \%$ had worsening symptoms. In a randomised pilot study, Cannell ${ }^{96}$ found that eccentric squat exercises were superior to leg curl/extension exercises in treatment of patellar tendinopathy. Given the natural history of patellar tendinopathy, these results are encouraging.

One of us (N M) advocates modified rest, with curtailment of the sport, or at least the component that causes the symptoms, to a level where pain is not experienced, and introduction of an alternative sport that does not load the tendon in the same way as the offending sport. Patients undergo a six week period of supervised physiotherapy including basic stretching and eccentric training as outlined above. By the end of six weeks, one third of the patients seen early enough in their disease process generally do not need further management. It should be stressed, however, that, given the referral system in the British Isles, most patients reach a specialist sports surgeon after six to nine months of symptoms. By this time, they will have already undergone several periods of rest, physiotherapy, and often, two or more peritendinous injections. In such cases, although the above period of physiotherapy is recommended, their chances of needing surgery are relatively high, probably in the region of $50 \%$.

\section{NSAIDs}

Although the benefit of NSAIDs in tendinopathies is not obvious, ${ }^{197}$ they are probably the most commonly used symptomatic therapy. ${ }^{98}$ In the only double blind placebo controlled study of the use of NSAIDs in tendinopathy, piroxicam did not benefit patients with Achilles tendinopathy. ${ }^{99}$ Topical ketoprofen reached the target tissue in patients with patellar tendinopathy, but the clinical efficacy was not assessed..$^{98}$

Although the use of "anti-inflammatory" medication seems paradoxical for a condition that is essentially degenerative, the NSAID family of drugs act in ways beyond their well known anti-inflammatory mode. ${ }^{100} 101$ In human cartilage in vitro, some NSAIDs stimulate, and others inhibit, glycosaminoglycan synthesis. ${ }^{102}$ If this also proves to be the case in vivo, it will provide a mechanism in tendons whereby NSAIDs could influence extracellular matrix. Thus it would appear premature to rule out any potential benefit of this class of medication merely because tendinopathy is not an inflammatory condition.

Table 4 Guidelines for corticosteroid injection (modified from ref 1)

\begin{tabular}{ll}
\hline Corticosteroid contraindicated & Corticosteroid may be indicated if: \\
\hline- Before competition & $\bullet$ Diluted with anaesthetic for diagnostic reasons and to minimise adverse effects \\
- In the acute phase of tendinopathy \\
$\begin{array}{l}\text { likely to be advanced } \\
\text { like the chronic phase of tendinopathy when tendon degeneration is }\end{array}$ & $\begin{array}{l}\text { - Followed by a 1-6 week rest period combined with a programme of gradual } \\
\text { strengthening before returning to activity }\end{array}$ \\
\hline
\end{tabular}


Table 5 Outcome of surgical management of jumper's knee

\begin{tabular}{lcccl}
\hline Author and reference & Very good & Good & Poor & Time to return to sport (mean) \\
\hline Colosimo $^{26}$ & 54 & 1 & 12 & Restrict 4-6 months and expect pain for 8-12 months \\
Ferretti $^{8}$ & 2 & 5 & 7 & Not given \\
Fritschy $^{36}$ & 17 & & 4 & Restrict training for 3 months, return to competition after 4 months \\
Karlsson $^{24}$ & 71 & & 7 & About 4 months \\
Karlsson $^{23}$ & 25 & & 2 & About 4 months \\
King $^{28}$ & 14 & & 3 & Not reported \\
Martens $^{31}$ & 19 & 10 & 3 & Restrict 4 months Return to sport from 3 to 8 months, mean 4 months \\
Orava $^{108}$ & 23 & & 11 & Light running after 2 months, full training after 3-4 months \\
Popp $^{109}$ & 7 & 3 & 1 & 3 months \\
Raatikainen $^{25}$ & 125 & & 13 & No running or jumping for 3 months \\
Roels $^{30}$ & 5 & 5 & & 3-8 months \\
\hline
\end{tabular}

Corticosteroids

Injection and infiltration-for example, iontophoresis - of corticosteroids is known to have a dramatic effect on symptoms arising from inflamed synovial structures. ${ }^{103}$ However, the role of corticosteroids in management of tendinopathy remains controversial. ${ }^{104} 105$ The guidelines of Jozsa and Kannus ${ }^{1}$ for appropriate use of corticosteroid injections should be adhered to in the absence of scientific evidence as to when these injections may be most appropriate (table 4). It is noteworthy that after injection a tendon is at increased risk of rupture until appropriate strengthening has been undertaken.

\section{Other medical treatments}

Recently, aprotinin has been trialled in the management of patellar tendinopathy. ${ }^{106}$ Aprotinin, an 85 amino acid $65 \mathrm{kDa}$ basic polypeptide extracted from bovine lungs, is a polyvalent inhibitor of the proteases collagenase, elastase, metalloprotease, kallikrein, plasmin, and cathepsin C. ${ }^{107}$ At least in the short term, aprotinin (two to four injections of $62500 \mathrm{IU}$ with local anaesthetic in the paratendinous space) seems to offer better chances of pain relief than corticosteroids. However, patients with an insertional tendinopathy fared less well than those with tendinopathy of the main body of the tendon. As aprotinin is an antiinflammatory agent, its administration is probably only warranted in athletes with relatively short duration of symptoms.

SURGICAL MANAGEMENT

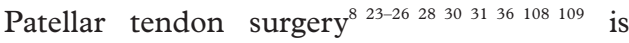
generally performed when the patient has not improved with at least six months of conservative management. ${ }^{25} 31108110 \mathrm{~A}$ variety of surgical methods for treatment of jumper's knee have been described. ${ }^{111}$ These include drilling of the inferior pole of the patella, resection of the tibial attachment of the patellar tendon with realignment, ${ }^{112}$ excision of macroscopic necrotic areas, ${ }^{25} 108$ repair of macroscopic defects, ${ }^{31}$ scarification-that is, longitudinal tenotomy/tenoplasty of the tendon, ${ }^{53}$ percutaneous needling, ${ }^{113}$ percutaneous longitudinal tenotomy ${ }^{114}$ and arthroscopic assisted decompression of the tendon, possibly with excision of the inferior pole of the patella. ${ }^{115}$ Surgical technique is based on the surgeon's opinion/ experience, as the pathophysiology of patellar tendinopathy is not known (table 5).

Several factors confound analysis of outcome of surgery. Surgeons differ in their diagnostic criteria, selection of cases for surgery, the actual operation performed, as well as in their postoperative protocols. Different types of surgery result in differences in the amount of bone either excised or drilled, the margin of normal tissue excised around the macroscopically degenerative tissue, the use or avoidance of longitudinal tenotomies, and the type of closure of the tendon after surgery. Intersurgeon technical ability is another major factor, the influence of which has never been studied. Furthermore, the results of surgery should not be evaluated in isolation as a prolonged period of rehabilitation usually ensues. ${ }^{353}$ Good results may be attributable in part to the relative rest, and therefore randomised studies are needed.

\section{Conclusion}

When treating patients with patellar tendinopathy, clinicians must emphasise to these patients that they have a degenerative, not an inflammatory, condition of their patellar tendon, which is most likely due to excessive load bearing. Clinical assessment is the key to diagnosis although the presence of abnormalities on ultrasonography or MR increases the likelihood that the patient's symptoms arise from the patellar tendon. Imaging appearances should not determine treatment. For the time being, treatment is based on clinical experience rather than on scientific rationale.

A variety of management modalities exist, including correction of the perceived underlying biomechanical problems, local physical modalities such as ice, and, when the patient is pain-free, a graduated strengthening programme emphasising functional exercises including eccentric training. Of the conservative measures available, eccentric training appears to be the most promising, but well designed controlled studies are urgently needed. Clinical experience suggests that in some patients peritendinous corticosteroid or aprotinin infiltration may be warranted as an adjunct to other appropriate treatments.

Surgery is indicated after a six to nine month trial of appropriate conservative management. Although we were not able to find a scientific report on it, percutaneous needling appears to be the least invasive procedure, followed by percutaneous longitudinal tenotomy. This latter procedure is advocated for tendinopathy in the mid-tendon, not at the patellar insertion. Open patellar tenotomy is the conventionally accepted surgical treatment of insertional patellar tendinopathy, but often requires six to nine months of rehabilitation. Arthroscopic 
debridement has been proposed, but, although early results are encouraging, its efficacy is still under scrutiny.

1 Józsa L, Kannus P. Human tendons. Champaign, IL: Human Kinetics, 1997:576

2 Gelberman R, Goldberg V, An K-N, et al. Tendon. In: Woo SL-Y, Buckwalter JA, eds. Injury and repair of the musculoskeletal soft tissues. Park Ridge, IL: American Academy of Orthopaedic Surgeons, 1988:5-40.

3 Henke P. The painful tendon: a pathophysiological approach. Aust Fam Physician 1987;16:772-6.

4 Hess GP, Cappiello WK, Poole RM, et al. Prevention and treatment of overuse tendon injuries. Sports Med 1989;8: 371-84.

5 Järvinen M. Epidemiology of tendon injuries in sports. Clin Sports Med 1992;11:493-504.

6 Kannus P. Tendons: a source of major concern in competitive and recreational athletes. [Editorial]. Scand $\mathcal{F} \mathrm{Med} S \mathrm{Sc}$ Sports 1997;7:53-4

7 Khan KM, Maffulli N. Tendinopathy: an Achilles' heel for athletes and clinicians. [Lead editorial]. Clin 7 Sport Med 1998;8:(in press)

8 Ferretti A, Ippolito E, Mariani P, et al. Jumper's knee. Am $\mathcal{f}$ Sports Med 1983;11:58-62.

9 McLoughlin RF, Raber EL, Vellet AD, et al. Patellar tendinitis: MR features, with suggested pathogenesis and proposed classification. Radiology 1995;197:843-8.

10 Scapinelli R. Blood supply of the human patella. F Bone foint Surg $[\mathrm{Br}]$ 1967;49:563-70.

11 Scapinelli R. Studies on the vasculature of the human knee joint. Acta Anat (Basel) 1968;70:305-31.

12 Astrom M, Westlin N. Blood flow in the normal Achilles tendon assessed by laser Doppler flowmetry. 7 Orthop Res tendon assessed

13 Oakes BW. The classification of injuries and mechanisms of injury repair and healing. In: Bloomfield J, Fricker PA, Fitch KD, eds. Textbook of science and medicine in sport. Melbourne: Blackwell Scientific Publications, 1992:20017.

14 Elliott DH. Structure and function of mammalian tendon. Biol Rev 1965;40:392.

15 O'Brien M. Functional anatomy and physiology of tendons. Clin Sports Med 1992;11:505-20.

16 Zernicke RF, Garhammer J, Jobe FW. Human patellartendon rupture: a kinetic analysis. F Bone foint Surg [Am] 1977;59:179-83.

17 Stanish WD, Curwin KS. Tendinitis. Its etiology and treatment. Toronto: Collamore Press, 1984.

18 Stanish WD, Rubinovich RM, Curwin S. Eccentric exercise in chronic tendinitis. Clin Orthop 1986;208:65-8.

19 McClay IS, Robinson JR, Andriacchi TP, et al. A profile of ground reaction forces in professional basketball. $\mathcal{F} A p p$ Biomater 1994;10:222-36.

20 Leadbetter WB. Cell-matrix response in tendon injury. Clin Sports Med 1992;11:533-78.

21 Clancy WGJ. Tendon trauma and overuse injuries. In Leadbetter WB, Buckwalter JA, Gordon SL, eds. Sportsinduced inflammation: clinical and basic science concepts. Park Ridge, IL: American Academy of Orthopaedic Surgeons, 1990:609-18.

22 Torstensen ET, Bray RC, Wiley JP. Patellar tendinitis: a review of current concepts and treatment. Clin $\mathcal{F}$ Sport Med 1994;4:77-82.

23 Karlsson J, Kalebo P, Goksor L-A, et al. Partial rupture of the patellar ligament. Am f Sports Med 1992;20:390-5.

24 Karlsson J, Lundin O, Lossing IW, et al. Partial rupture of the patellar ligament. Results after operative treatment. $A m$ f Sports Med 1991:19:403-8.

25 Raatikainen T, Karpakka J, Puranen J, et al. Operative treatment of partial rupture of the patellar ligament. A study of 138 cases. Int $\mathcal{F}$ Sports Med 1994;15:46-9.

26 Colosimo AJ, Bassett FH. Jumper's knee: diagnosis and treatment. Orthopaedic Reviews 1990;29:139-49.

27 Yu JS, Popp JE, Kaeding CC, et al. Correlation of MR imaging and pathologic findings in athletes undergoing surgery for chronic patellar tendinitis. AfR Am f Roentgenol 1995;165:115-18.

28 King JB, Perry DJ, Mourad K, et al. Lesions of the patellar ligament. F Bone foint Surg [Br] 1990;72:46-8.

29 Fritschy D, Wallensten R. Surgical treatment of patellar tendinitis. Knee Surg Sports Traumatol Arthrosc 1993;1:131-

30 Roels J, Martens M, Mulier JC, et al. Patellar tendinitis (jumper's knee). Am f Sports Med 1978;6:362-8.

31 Martens M, Wouters P, Burssens A, et al. Patellar tendonitis: pathology and results of treatment. Acta Orthop Scand 1982;53:445-50.

32 Khan KM, Bonar F, Desmond PM, et al. Patellar tendinosis (jumper's knee): findings at histopathologic examination, US and MR imaging. Radiology 1996;200:821-7.

33 Movin T, Gad A, Reinholt FP, et al. Tendon pathology in long-standing achillodynia. Biopsy findings in 40 patients. Acta Orthop Scand 1997;68:170-5.

34 Astrom M, Rausing A. Chronic Achilles tendinopathy. A survey of surgical and histopathologic findings. Clin Orthop 1995;316:151-64.

35 Blazina ME, Kerlan RK, Jobe FW, et al. Jumper's knee. Orthop Clin North Am 1973;4:665-78.

36 Fritschy D, de Gautard R. Jumper's knee and ultrasonography. Am F Sports Med 1988;16:637-40.
37 Myllymäki T, Bondestam S, Suramo I, et al. Ultrasonography of jumper's knee. Acta Radiol 1990;31:147-9.

38 Bodne D, Quinn SF, Murray WT, et al. Magnetic resonance imaging of chronic patellar tendinitis. Skeletal Radiol 1988; $17 \cdot 24-8$

39 Davies SG, Baudouin CJ, King JB, et al. Ultrasound, computed tomography and magnetic resonance imaging in patellar tendinitis. Clin Radiol 1991;43:52-6.

40 Mourad K, King J, Guggiana P. Computed tomography and ultrasound imaging of jumper's knee: patellar tendinitis. Clin Radiol 1988;39:162-5.

41 Kujala UM, Aalto T, Osterman K, et al. The effect of playing volleyball on the knee extensor mechanism. Am $\mathcal{F}$ Sports Med 1989;17:766-70.

42 Kannus P, Jozsa L. Histopathological changes preceding spontaneous rupture of a tendon. F Bone foint Surg [Am] 1991;73:1507-25.

43 Waterston SW, Maffulli N, Ewen SWB. Subcutaneous rupture of the Achilles tendon: basic science and some aspects of clinical practice. Br f Sports Med 1997;31:289-98.

44 Withdrawn

45 Kolliker A. Handbuch der Gewebelehre des Menschen. Leipzig: W Engelman, 1855:198-9.

46 Rudolph G. Histochemische Untersuchungen zum Stoffwechsel des bradytrophen Gewebes. Verh Dtsch Ges Pathol 1964:48:325-9.

47 O'Brien M. Structure and metabolism of tendons. Scand $\mathcal{F}$ Med Sci Sports 1997;7:55-61.

48 Peacock EE. A study of the circulation of normal tendons and healing grafts. Ann Surg 1959;149:415

49 Gerber G, Gerber G, Altman KI. Studies on the metabolism of tissue proteins. I. Turnover of collagen labelled with proline-U-C ${ }^{14}$ in young rats. F Biol Chem 1960;235:2653-6.

50 Peacock EEJ, van Winkle WJ. Surgery and biology of wound repair. Philadelphia: WB Saunders, 1970:334-6.

51 Williams IF. Cellular and biochemical composition of healing tendon. In: Jenkins DHR, ed. Ligament injuries and their treatments. Rockville, MD: Aspens Systems Corporation, 1985:43-57

52 Johnson DP. Magnetic resonance imaging of patellar tendonitis. F Bone foint Surg [Br] 1996;78:452-7.

53 Puddu G, Cipolla M, Franco V et al. Tendinitis. In: Fox JM, Del Pizzo W, ed. The patellofemoral joint. New York: McGraw-Hill, 1993:

54 Maffulli N, Dymond NP, Regine R. Surgical repair of ruptured Achilles tendon in sportsmen and sedentary patients: a longitudinal ultrasound assessment. Int $\mathcal{f}$ Sports Med 1990;11:78-84.

55 Ferretti A. Epidemiology of jumper's knee. Sports Med 1986;3:289-95.

56 Pezzullo DJ, Irrgang JJ, Whitney SL. Patellar tendonitis: jumper's knee. Fournal of Sports Rehabilitation 1992;1:5668.

57 Lian O, Holen KJ, Engebrestson L, et al. Relationship between symptoms of jumper's knee and the ultrasound characteristics of the patellar tendon among high level male volleyball players. Scand F Med Sci Sports 1996;6:291-6.

58 Lian O, Engebretsen L, Ovrebo RV, et al. Characteristics of the leg extensors in male volleyball players with jumper's knee. Am $\mathcal{F}$ Sports Med 1996;24:380-5.

59 Cook JL, Khan K, Harcourt PR, et al. A cross-sectional study of 100 cases of jumper's knee managed conservatively and surgically. Br f Sports Med 1997;31:332-6.

60 McConnell J. The management of chondromalacia patellae: a long term solution. Australian fournal of Physiotherapy 1986;32:215-23.

61 Brukner P, Khan K. Clinical sports medicine. Sydney: McGraw-Hill, 1993.

62 Nirschl RP. Elbow tendinosis/tennis elbow. Clin Sports Med 1992;11:851-70.

63 Visentini PJ, Khan KM, Cook JL, et al. The VISA score: an index of the severity of jumper's knee (patellar tendinosis) fournal of Science and Medicine in Sport 1998;1:22-8.

64 Beltran J, Noto AM, Herman LJ, et al. Tendons: high-fieldstrength surface coil MR imaging. Radiology 1987;162: 735-40.

65 Fornage BD, Rifkin MD. Ultrasound examination of tendons. Radiol Clin North Am 1988;26:87-107.

66 Richardson ML, Selby B, Montana MA, et al. Ultrasonography of the knee. Radiol Clin North Am 1988;26:63-75.

67 Tietz CC. Ultrasonography in the knee: clinical aspects. Radiol Clin North Am 1988;26:55-62.

68 Maffulli N, Regine R, Carrillo F, et al. Ultrasonographic scan in knee pain in athletes. Br f Sports Med 1992;26:936.

69 Maffulli N, Regine R, Angelillo M, et al. Ultrasound diagnosis of Achilles tendon pathology in runners. Br $\mathcal{F}$ Sports Med 1987;21:158-62.

70 Sandmeier R, Renstrom P. Diagnosis and treatment of chronic tendon disorders in sport. Scand 7 Med Sci Sports 1997;7:96-106.

71 Kiss ZS, Kellaway D, Cook J, et al. Postoperative patellar tendon healing: an ultrasound study. Australasian Radiology 1998;42:28-32.

72 Borre A, Berra G, Ravera R, et al. Ultrasonography study of the patellar tendon following bone-tendon-bone anterior cruciate ligament reconstruction arthroscopy. [Italian]. Radiol Med (Torino) 1995;89:604-7.

73 Adriani E, Mariani PP, Maresca G, et al. Healing of the patellar tendon after harvesting of its mid-third for anterior cruciate ligament reconstruction and evolution of the unclosed donor site defect. Knee Surg Sports Traumatol Arthrosc 1995;3:138-43. 
74 Wiley JP, Bray RC, Wiseman DA, et al. Serial ultrasonographic imaging evaluation of the patellar tendon after harvesting its central one third for anterior cruciate

75 Cook JL, Khan KM, Harcourt PR, et al. Patellar tendon ultrasonography in asymptomatic active athletes reveals hypoechoic regions: a study of 320 tendons. Clin $\mathcal{F}$ Sport Med 1998;8:73-7.

76 Kalebo P, Sward L, Karlsson J, et al. Accuracy of ultrasonography in the detection of partial patellar ligament ruptures (jumper's knee). Skeletal Radiol 1991;20 285-9.

77 Khan KM, Cook JL, Kiss ZS, et al. Patellar tendon ultrasonography and jumper's knee in elite female basketball players: a longitudinal study. Clin $\mathcal{F}$ Sport Med 1997; 199-206.

78 Maffulli N, Testa V, Capasso G, et al. Results of percutaneous longitudinal tenotomy in Achilles tendinopathy in middle- and long-distance runners. Am f Sports Med 1997; 25:835-40

80 Khan KM, Visentini PJ, Cook JL, et al. Open patellar

Khan KM, Visentini PJ, Cook JL, et al. Open patellar
tenotomy for jumper's knee: MR and ultrasound correlatenotomy for jumper's knee: MR and ultrasound correlation with clinical
$1998 ; 30: S 300$.

81 El-Khoury GY, Wira RL, Berbaum KS, et al. MR imaging of patellar tendinitis. Radiology 1992;184:849-54.

82 Movin $\mathrm{T}$, Kristoffersen-Wiberg M, Shalabi A, et al. Intratendinous alterations as imaged by ultrasound and contrast medium enhanced magnetic resonance in chronic achillodynia. Foot Ankle Int 1998;19:311-17.

83 Miniaci A, Dowdy PA, Willits KR, et al. Magnetic resonance imaging evaluation of the rotator cuff tendons in the asymptomatic shoulder. Am 7 Sports Med 1995;23:142-5.

84 Pope CF. Radiologic evaluation of tendon injuries. Clin Sports Med 1992;11:579-99.

85 Erickson SJ, Cox IH, Hyde JS, et al. Effect of tendon orientation on MR imaging signal intensity: a manifestation of the 'magic angle' phenomenon. Radiology 1991;181:389the

86 Erickson SJ, Prost RW, Timins ME. The 'magic angle' effect: background physics and clinical relevance. Radiology 1993;188:23-5.

87 Ferretti A, Papandrea P, Conteduca F. Knee injuries in volleyball. Sports Med 1990;10:132-8.

88 Zuluaga M, Briggs C, Carlisle J, et al, eds. Sports physiotherapy. Applied science and practice. Melbourne: Churchill Livingstone, 1995.

89 Lee E, Maffulli N, Li CK, et al. Pulsed magnetic and electromagnetic fields in experimental Achilles tendonitis in the rat: a prospective randomised study. Arch Phys Med Rehabil 1997;78:399-404.

90 Pellechia G, Hamel H, Behnke P. Treatment of infrapatellar tendinitis: a combination of modalities and transverse friction massage versus iontophoresis. fournal of Sport Rehabilitation 1994;3:1315-45.

91 Testa V, Ruggiu M, Capasso G. Fibrolisi diacutanea: una tecnica diagnostica e terapeutica nelle patologie croniche tecnica diagnostica e terapeutica nelle patologie croniche 49:89-94.

92 Curwin S, Stanish WD. Tendinitis: its etiology and treatment. Lexington: Collamore Press, 1984

93 Fyfe I, Stanish WD. The use of eccentric training and stretching in the treatment and prevention of tendon injuries. Clin Sports Med 1992;11:601-24.

94 El Hawary R, Stanish WD, Curwin SL. Rehabilitation of tendon injuries in sport. Sports Med 1997;24:347-58.
95 Curwin S. The aetiology and treatment of tendinitis. In: Harries M, Williams C, Stanish WD, et al, eds. Oxford textbook of sports medicine. Oxford: Oxford University Press, 1994:312-33.

96 Cannell LJ. The effects of an eccentric-type exercise versus a concentric-type exercise in the management of chronic patellar tendonitis. Masters Thesis, University of British Columbia, 1982.

97 Galloway MT, Jokl P, Dayton OW. Achilles tendon overuse injuries. Clin Sports Med 1992;11:771-82.

98 Rolf C, Movin T, Engstrom B, et al. An open, randomized study of ketoprofen in patients in surgery for Achilles or patellar tendinopathy. $\mathcal{F}$ Rheumatol 1997;24:1595-8.

99 Astrom M, Westlin N. No effect of piroxicam on Achilles tendinopathy. A randomized study of 70 patients. Acta Orthop Scand 1992;63:631-4

100 Weiler JM. Medical modifiers of sports injury: the use of nonsteroidal anti-inflammatory drugs (NSAIDs) in sports soft tissue injury. Clin Sports Med 1992;11:625-44.

101 Almekinders LC. The efficacy of nonsteroidal antiinflammatory drugs in the treatment of ligament injuries. Sports Med 1990;9:137-42.

102 Dingle JT. The effect of NSAIDs on human cartilage glycosaminoglycan synthesis. Eur $\mathcal{f}$ Rheumatol Inflamm $1996 ; 16: 47-52$

103 Leadbetter WB. Tendon overuse injuries: diagnosis and treatment. In: Renstrom PAFH, ed. Sports injuries. Basic principles of prevention and care. London: Oxford, 1993:44976.

104 Shrier I, Matheson GO, Kohl HW. Achilles tendonitis: are corticosteroid injections useful or harmful? Clin $\mathcal{F}$ Sport Med 1996;6:245-50.

105 Fredberg U. Local corticosteroid injection in sport: a review of literature and guidelines for treatment. Scand 7 Med Sci Sport 1997;7:131-9.

106 Capasso G, Testa V, Maffulli N, et al. Aprotinin, corticosteroids and normosaline in the management of patellar tendinopathy in athletes: a prospective randomized study. Sports Exercise and Injury 1997;3:111-15.

07 Dayer JM. Chronic inflammatory joint diseases: natural nhibitors of IL-1 and TNF-alpha. F Rheumatol 1991; 18(suppl):71-5

108 Orava S, Osterback L, Hurme M. Surgical treatment of patellar tendon pain in athletes. $\mathrm{Br} \mathcal{F}$ Sports Med 1986;20:167-9.

109 Popp JE, Yu JS, Kaeding CC. Recalcitrant patellar tendinitis. Magnetic resonance imaging, histologic evaluation and surgical treatment. Am $\mathcal{F}$ Sports Med 1997;25:218-22.

110 Saillant G, Rolland E, Garçon P, et al. Surgical treatment of patellar tendinitis. A series of 80 cases. Fournal of Traumatology in Sport 1991;8:114-20.

111 Binfield PM, Maffulli N. Surgical management of common tendinopathies. Sports Exercise and Injury 1997;3: $116-22$.

112 Biedert R, Vogel U, Friedrichs NF. Chronic patellar tendinitis: a new surgical treatment. Sports Exercise and Injury 1997;3:150-4.

113 Leadbetter WB, Mooar PA, Lane GJ, et al. The surgical treatment of tendinitis: clinical rationale and biologic basis. Clin Sports Med 1992;11:679-712.

114 Testa V, Capasso G, Maffulli N, et al. Ultrasound guided percutaneous longitudinal tenotomy for the management of patellar tendinopathy. Med Sci Sports Exerc (in press)

115 Johnson DP. Arthroscopic surgery for patellar tendonitis: a new technique. Arthroscopy 1998;14(suppl 1):44. 